\title{
EXPERIMENTAL MEASUREMENTS ON CONFIGURATIONAL FREE ENERGY CHANGE OF THE GRAPHITE-GLASSY CARBON EQUILIBRIUM
}

\author{
S. K. DAS* and E. E. HUCKE \\ Department of Materials and Metallurgical Engineering, The University of Michigan, Ann Arbor, Michigan 48104 , \\ U.S.A.
}

(Received 24 May 1974)

\begin{abstract}
A precise thermodynamic measurement of the equilibrium: $C_{\mathrm{graphite}}=\mathrm{C}_{\mathrm{glassy} \text { carton }}$ employing a solid oxide electrolyte in the temperature range $650^{\circ}-1150^{\circ} \mathrm{C}$ was carried out to gain structural information on glassy carbons. The measured Gibbs free energy change yields configurational (residual quantities at zero Kelvin) enthalpy and entropy differences, which represent a two parameter measure of the structural differences between a given glassy carbon and graphite, since the above reaction involves vanishingly small differences in composition, specific heat, and hence vibrational contributions. Many of the experimental and commercially available samples of glassy carbons studied exhibited at elevated temperature thermodynamic carbon activities lower than graphite. For various samples studied, the zero point entropy varied from 3.1 to $11.3 \mathrm{cal} / \mathrm{g}$-mole ${ }^{\circ} \mathrm{K}$. The thermodynamic parameters are correlated with X-ray and density measurements. The configurational enthalpy and entropy changes are interpreted in terms of strain related and atomic disorder parameters, respectively.
\end{abstract}

\section{INTRODUCTION}

The structure, properties, and application of carbon have intrigued crystallographers, scientists, and engineers for decades. Part of the fascination stems from the fact that, in addition to its well-defined crystalline allotropic forms, carbon can take any number of quasi or para-crystalline forms in which the structure is highly disordered.

Disordered carbons which are usually encountered in particulate form such as carbon blacks and soot have been structurally described as "washed out" graphite. However, the "hard" nongraphitizing carbons, which include glassy carbon, cellulose carbon, and several types of carbon fibers and chars, are obtained in massive shapes and sizes from a wide range of natural and synthetic precursors (cancerous human tissue to polyfurfural alcohol), and retain a very imperfect structure even after prolonged exposure to high temperature. In fact, a three dimensional graphitic structure in these disordered carbons can not be obtained without unusual means.

A relatively new form of pure carbon, called "glassy", "vitreous" or "glass-like", gains its name from its resemblance to black glass on a fractured surface rather than a detailed knowledge of its structure. Unfortunately, very sketchy and conflicting reports have been published

*This paper is based on a portion of a thesis submitted by S. K. DAS in partial fulfillment of the requirements of the degree of Doctor of Philosophy at The University of Michigan, Ann Arbor. on the atomic structure of glassy carbons. With a better understanding of its structrual variations, extension of the range of properties achievable should be possible.

Although there are diverse methods for gaining information about the structure of solids on various size scales, each has its drawbacks in sensitivity, interpretation, and in ease of measurement when applied to carbon which is not well crystallized. As a result, an attempt was made to gain structural information through a precise thermodynamic measurement. Since the reaction $\mathrm{C}_{\text {graphite }} \rightleftarrows \mathrm{C}_{\text {glassy carbon }}$ involves no change in composition, the enthalpy $(\Delta \mathrm{H})$ and entropy $(\Delta \mathrm{S})$ differences represent a two parameter measure of the structural differences of a given glassy carbon relative to graphite.

An accurate determination of the Gibbs free energy change for the equilibrium over a range in temperature allows the separate evaluation of both $\Delta H$ and $\Delta S$. With the specific heat data for graphite and glassy carbon, a separation of both the enthalpy and entropy into vibrational and configurational components can be made. This procedure thus yields a four parameter measure (two parameter if the difference in vibrational contributions are small) of the average difference between a given glassy carbon structure and that of graphite. The purely configurational enthalpy and entropy have a very straightforward meaning as numerical measures of the difference in bonding energy due to disordering, and the degree of disordering respectively. Differences in the 
vibrational contributions result from the factors that determine the specific heat.

In principle it is possible to calculate the configurational entropy for various simple structural models and compare for consistency with the measured value. This procedure can rule out some models, but never establish the existence of a given model. However, whatever the real structure, the data become a numerical measure of the disorder of a given carbon relative to graphite.

\section{EXPERIMENTAL TECHNIQUE}

A solid oxide electrolyte $\left(\mathrm{ZrO}_{2}-15\right.$ mole per cent $\left.\mathrm{CaO}\right)$ cell was employed to measure the oxygen partial pressure in equilibrium with graphite and glassy carbon at a given temperature and total pressure in equilibrium with graphite and glassy carbon at a given temperature and total pressure. Solid oxide electrolytes have experienced an intense level of activity since the rebirth of interest supplied by the pioneering work of Kiukkola and Wagner[1]. A few excellent reviews of the principles and applications of solid oxide electrolytes have been published $[3,4]$. The calcia doped zirconia solid electrolyte is known to satisfy the necessary experimental conditions of conductivity and stability in the temperature and oxygen partial pressure range of interest in this work [2].

Independent of any specific knowledge of the mechanism of ionic conduction in a crystalline electrolyte which exhibits exclusive ionic conduction (defined as ionic transference number, $t_{\text {ion }}>0.99$ ), a simple consideration of energy conversion provides the relationship between the reversible cell potential $E$ and the standard Gibbs free change $\Delta G$ of the virtual chemical reaction of the Cell C-I

$$
\begin{gathered}
p_{\mathrm{O}_{2}}^{\mathrm{I}} / \text { Solid Electrolyte } / \mathrm{P}_{\mathrm{O}_{2}}^{\mathrm{II}}, \\
\Delta G=-n E F=R T \ln \left[\frac{p_{\mathrm{O}_{2}}^{\mathrm{II}}}{p_{\mathrm{O}_{2}}}\right]^{1 / 2},
\end{gathered}
$$

where $n$ is the equivalent of charge passed through the external circuit, $F$ is the Faraday's constant, and $p_{\mathrm{O}_{2}}^{\mathrm{I}}$ and $p_{\mathrm{O}_{2}}^{\mathrm{II}}$ are the oxygen partial pressures of two electrodes. The application of the Gibbs-Helmholtz relation to the temperature dependence of the cell voltage provides values of $\Delta H$ and $\Delta S$ of the virtual cell reaction.

Solid electrolyte cells were operated for the direct determination of the standard free energy change of the equilibrium:

$$
\mathrm{C}_{\text {graphite }} \rightleftarrows \mathrm{C}_{\text {glassy carbon }}
$$

Available data for the heat capacitics of graphite and various glassy carbons show that any vibrational contributions to the free energy in the range of temperature of interest will be $\pm 10 \mathrm{cal} / \mathrm{g}$-mole or less [5,6], which is completetely negligible. Therefore, the measured differences can be considered wholly configurational and separated into enthalpy and entropy terms. Disorder such as mixed bonding or strained bonds should cause changes in the configurational enthalpy and a definite increase in the configurational entropy, which can be directly interpreted as numerical disorder parameters. Such techniques have already been applied in the case of polymers to determine the degree of crystallinity, where configurational (residual) entropies up to $5 \mathrm{cal} / \mathrm{g}$-mole- ${ }^{\circ} \mathrm{K}$ were found [7]. Configurational enthalpies of about $1500 \mathrm{cal} / \mathrm{g}$-mole have been previously measured between glassy carbon and graphitc by the heat of combustion method [8]. Using an isothermal calorimeter for measuring the heat of formation of potassium graphite, $\mathrm{C}_{8} \mathrm{~K}$, rather large energy differences have also been measured between graphite in hexagonal and rhombohedral stacking [9]. In addition, Gordon [10] has pointed out from an examination of the discrepancy between experimental determinations of the equilibrium constant for the Boudouard reaction: $\mathrm{C}(\mathrm{s})+\mathrm{CO}_{2}(\mathrm{~g})=2 \mathrm{CO}(\mathrm{g})$ and the values derived from heat of combustion and spectroscopic data that a residual entropy of $0.5 \mathrm{cal} / \mathrm{g}$-mole may exist in near perfect graphite. The results of the solid electrolyte cell are considerably more accurate than the previous methods and yield both $\Delta H$ and $\Delta S$.

The solid electrolyte cell C-II involved measuring the difference in oxygen partial pressure existing at opposite sides of the electrolyte where this pressure is additionally constrained to be in equilibrium with $\mathrm{CO}$ and $\mathrm{CO}_{2}$ and the appropriate solid carbons. If a difference in $p_{\mathrm{O}_{2}}$ exists between the two sides at equilibrium with the same temperature and total pressure after starting with either $\mathrm{CO}$ or $\mathrm{CO}_{2}$ or $\mathrm{O}_{2}$, then it can only be due to a difference in activity of the two carbons. Carbon activities in glassy carbon were measured with reference to graphite as a standard state for carbon using the following cell C-II:

$$
\mathrm{Pt} / \mathrm{C}_{\mathrm{I}}(\mathrm{s}), \mathrm{CO}(\mathrm{g}), \mathrm{CO}_{2}(\mathrm{~g}) / / \text { S.E. } / / \mathrm{C}_{\mathrm{II}}(\mathrm{s}), \mathrm{CO}(\mathrm{g}), \mathrm{CO}_{2}(\mathrm{~g}) / \mathrm{Pt}
$$

$$
\begin{array}{cc}
\text { Glassy Carbon } & \text { Graphite } \\
p_{\mathrm{O}_{2}}^{l} & p_{\mathrm{O}_{2}}^{\mathrm{II}}
\end{array}
$$

Temperature Range: $600-1150^{\circ} \mathrm{C}$

Oxygen Partial Pressure Range:

$$
10^{-24}\left(600^{\circ} \mathrm{C}\right)-10^{-17}\left(1150^{\circ} \mathrm{C}\right) \text { atm. }
$$

The emf $E$ of cell C-II can be related to $\left[p_{\mathrm{CO}_{2}} / p_{\mathrm{CO}}\right)^{1}$ and $\left[p_{\mathrm{CO}_{2}} / p_{\mathrm{CO}}\right]^{\text {II }}$ which can be subsequently related to carbon activities in two different forms and the standard Gibbs free energy change of the reaction: $\mathrm{C}(\mathrm{s})+\mathrm{CO}_{2}(\mathrm{~g})=$ $2 \mathrm{CO}(\mathrm{g})$. 


$$
\left[\frac{p_{\mathrm{O}_{2}}^{\mathrm{II}}}{p_{\mathrm{O}_{2}}^{\mathrm{I}}}\right]^{1 / 2}=\frac{\left[\frac{p_{\mathrm{CO}_{2}}}{p_{\mathrm{CO}}}\right]^{\mathrm{II}}}{\left[\frac{p_{\mathrm{CO}_{2}}}{p_{\mathrm{CO}}}\right]^{1}}=e^{-2 E F / R T}
$$

The quadratic equation, $p_{\mathrm{CO}}^{2}=(\mathrm{K})\left(a_{c}\right)(\mathrm{P})-(\mathrm{K})\left(p_{\mathrm{CO}}\right)\left(a_{c}\right)$ relating the equilibrium constant $K$ of the producer gas reaction, and $p_{\mathrm{CO}}+p_{\mathrm{CO}_{2}}=P\left(p_{\mathrm{O}_{2}} \ll p_{\mathrm{CO}_{2}}+p_{\mathrm{CO}}\right)$ can be solved, and the result can be expressed as:

$$
\frac{\left[\frac{p_{\mathrm{CO}_{2}}}{p_{\mathrm{CO}}}\right]^{11}}{\left[\frac{p_{\mathrm{CO}_{2}}}{p_{\mathrm{CO}}}\right]^{1}}=\frac{-1+\left[\left(1+\frac{4 P}{K a_{\mathrm{C}_{11}}}\right)^{1 / 2}\right]}{-1+\left[\left(1+\frac{4 P}{K a_{\mathrm{C}_{1}}}\right)^{1 / 2}\right]}
$$

where

$$
P=\text { Total Atmospheric Pressure }
$$

$\left[\frac{p_{\mathrm{CO}_{2}}}{p_{\mathrm{CO}}}\right]=$ Ratio of equilibrium partial pressures of $\mathrm{CO}_{2}$ and

$$
a_{\mathrm{c}}=\text { Thermodynamic Carbon Activity }
$$

and subscripts and superscripts I and II refer to the thermodynamic quantities at left hand and right hand electrodes, respectively. It can be readily shown from the inspection of equations 2 and 3 that the electrode with lower carbon activity is at higher oxygen potential.

One can obtain an expression for $a_{5}$, with respect to $a_{\mathrm{C}_{\mathrm{II}}}=1 \cdot 00$, by substituting equation 3 in 2 .

$$
a_{\mathrm{C}_{1}}=\left[\frac{K}{P}(X Y)(1+X Y)\right]^{-1}
$$

where

$$
\begin{aligned}
X=\left[p_{\mathrm{CO}_{2}} / p_{\mathrm{CO}}\right]^{\mathrm{II}} & =\frac{\left[-1+\left(1+\frac{4 P}{K}\right)^{1 / 2}\right]}{2} \\
Y & =e^{2 E F / R T}
\end{aligned}
$$

The values of the equilibrium constant $K$ used here were previously measured by the authors[11] employing a similar electrochemical method. The expression for the equilibrium constant is: $\log K=-(9180 / T)+9 \cdot 36$.

Once the emf of cell C-II is measured as a function of temperature, $\Delta G, \Delta H$, and $\Delta S$ of the glassy carbongraphite transition can be readily calculated.

\section{EXPERIMENTAL METHOD}

\subsection{Cell assembly}

The cell arrangement is illustrated schematically in Fig.
1. The electrode isolation requirement is best fulfilled by the complete enclosure of one electrode in an impervious solid electrolyte (SE) tube.

The SE tube sat firmly and tightly in the graphite crucible, the platinum electrode being sandwiched between the outer face of the SE tube and the inner face of the graphite crucible. The graphite crucible served as support for the SE tube, provided excellent electrical contact, and also became the reference electrode. In all the experiments the outside electrode was the reference graphite electrode and the inside electrode was the unknown electrode, for which the oxygen partial pressure was measured.

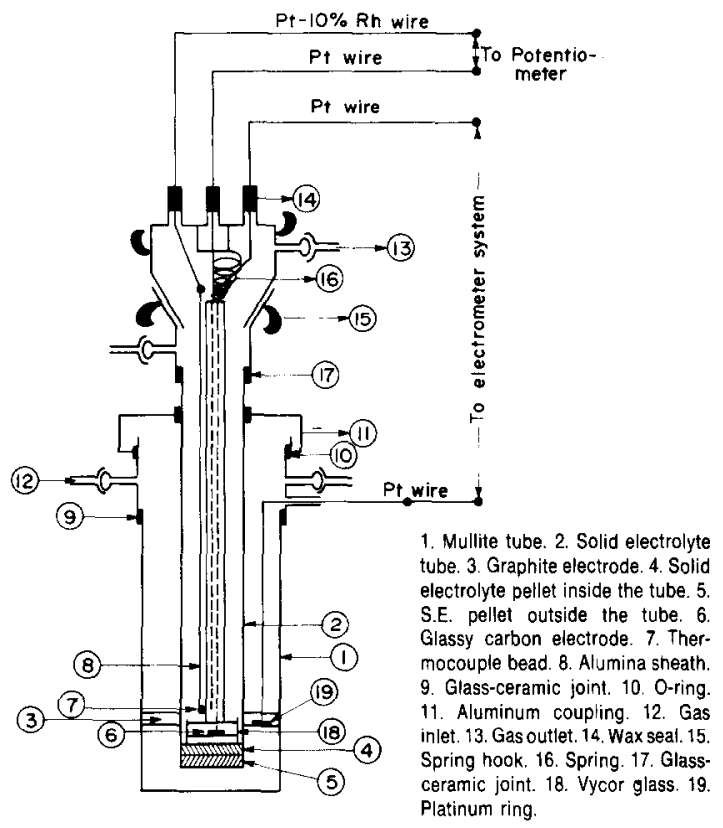

Fig. 1. Cell assembly for solid electrolyte systems.

Suitable size electrode pellets were pressed inside the tube by means of a spring action transmitted through an alumina push rod. The Pt lead wire for the inner electrode, contacting the electrode through a spiral made at that end of the wire, was passed through one of the holes of the push-rod. The Pt-10 per cent Rh thermocouple wire was covered by alumina protection tubes and the other $\mathrm{Pt}$ thermocouple wire was passed through the other hole in the alumina push rod. The inside and outside faces of the SE tube were protected against any electrode contamination by placing two SE pellets, one on each side of the tube between the electrode and tube face. Separate inlets and outlets for gases were provided for both inside and outside chambers. This satisfied the requirement of total isolation of the two electrode chambers.

A Lindberg hevi-duty 3-zone horizontal wire-wound 
furnace capable of reaching $1200^{\circ} \mathrm{C}$ was used for most of the experiments. The desired temperature was controlled within $+1{ }^{\circ} \mathrm{C}$ by employing a solid state digital controller.

The cell potentials were measured by a multi-purpose electrometer (Kiethley Model $600 \mathrm{~A}$ ) and a differential voltmeter (Kiethley Model 660). The electrometer was an ultra-high impedance instrument with an input resistance of $10^{14} \Omega$ as compared to $500 \Omega$ for the potentiometer when off balance, and an infinite resistance when balanced. The instrument readings were checked against a known standard voltage source with agreement better than $\pm 0.1 \mathrm{mV}$. Temperature potentials were measured with an L \& N Model K-2 potentiometer.

\subsection{Sample preparation}

The graphite cylinders were Union Carbide AGSR grade. The AGSR is extruded, fine grained general purpose graphite. It is made of calcined petroleum coke, graphitized over $2500^{\circ} \mathrm{C}$, and has an average ash content of 0.12 per cent and a xylene immersion density of $2.22 \mathrm{~g} / \mathrm{c}$.c. Union Carbide recrystallized pyrolytic graphite was also used for a carbon reference electrode. It is an ultra-pure, well crystallized graphite with a mosaic spread of only $0.8^{\circ} \pm 0.2^{\circ}$ (ZYB grade).

Most of the carbon samples were prepared at The University of Michigan. In general these glassy carbons are porous with a surface area of about $60 \mathrm{~m}^{2} / \mathrm{g}$ for samples heat treated in the neighborhood of $2000^{\circ} \mathrm{C}$. The qualitative spectroscopic analysis of these glassy carbon samples showed $\mathrm{Si}, \mathrm{Na}, \mathrm{Fe}, \mathrm{Mg}, \mathrm{Zr}$, and $\mathrm{Ni}$ as major impurities (50-500 ppm) and $\mathrm{Ca}, \mathrm{Al}, \mathrm{Ti}, \mathrm{Co}, \mathrm{Cu}$, and $\mathrm{Cr}$ as minor impurities ( $0-10 \mathrm{ppm})$. Additional samples of glassy carbon werc supplied by Bcckwith Carbon Company and produced from resin $\mathrm{H}-54$ of the Hercules Chemical Company.

The glassy carbon samples made from polyfurfural alcohol based resin were subjected to a two stage heat-treatment. The low temperature heat treatment up to $700^{\circ} \mathrm{C}$ was carried out in a graphite resistance furnace in a stream of flowing nitrogen. The average heating rate to $700^{\circ} \mathrm{C}$ was $5^{\circ} \mathrm{C} / \mathrm{h}$. The final heat treatment cycle was done at a relatively faster rate $\left(200^{\circ} \mathrm{C} / \mathrm{h}\right.$.) to HTT of $1000^{\circ}-2000^{\circ} \mathrm{C}$ in either vacuum $\left(\simeq 10^{-7} \mathrm{~atm}\right.$.) or in an atmosphere of flowing nitrogen.

\subsection{Cell operation}

The starting of each run consisted of assembling the cell, connecting it to the gas purification system, filling the cell chambers with $\mathrm{CO}_{2}$ gas and finally starting the heating cycle. The chambers of the cell were evacuated separately for about one-half hour then filled with $\mathrm{CO}_{2}$.

*Gupta, M. R. (The University of Michigan 1974) Private Communication.
The cell was heated at a rate of about $200^{\circ} \mathrm{C} / \mathrm{h}$. After the desired temperature was reached, the cell was allowed to equilibrate for about $4 \mathrm{~h}$. The electromotive force was recorded at intervals of $30 \mathrm{~min}$ and if the variations were within $\pm 1 \mathrm{mV}$ over a period of $2-3 \mathrm{~h}$, the emf values were considered to be steady.

The criteria adopted for equilibrium was that any small cell potential variations be random. If these variations were systematic, sufficient time was allowed until steady cell potential was achieved. The reversibility of cell voltage was checked at each temperature by polarizing the cell in both directions. This was accomplished by intentionally measuring the cell potential using an $\mathrm{L} \& \mathrm{~N}$ Model K-2 potentiometer or by passing small currents in both directions from a battery for about $5-10 \mathrm{sec}$. When the cell was at equilibrium the cell potential came back to its original reading in less than $15 \mathrm{~min}$.

The temperature was then changed in steps of $50^{\circ} \mathrm{C}$, and the cell was allowed to equilibrate for about $3 \mathrm{~h}$ at high temperatures and about $6 \mathrm{~h}$ at low temperatures. The cell was evacuated at each temperature and then both chambers were filled with $\mathrm{CO}_{2}$ gas. This was done to avoid any deposition of carbon on electrodes during cooling.

After a sufficient amount of data were obtained in a given run, the furnace was slowly cooled to room temperature. The cell components were visually inspected and the electrodes weighed to record the total weight loss.

\subsection{X-ray diffraction measurements}

Several useful structural measures of the state of glassy carbon were derived from wide angle $X$-ray diffraction. The measurement of the "crystallite size" and "interlayer spacing" was done to obtain an approximate idea of the extent of graphitization. The apparent diameter, $L_{a}$, and the height, $L_{c}$, of the crystal were obtained by measurement of the broadening of the appropriate diffraction peaks. The interlayer spacing was obtained from the diffraction angle at which the corresponding peak was found. The broadening parameters in this study were evaluated directly from the experimental diffractometer traces. However, as pointed out by Short and Walker [12], even with this so-called crude analysis, the value of $L_{\mathrm{c}}$ is quite satisfactory. The $\mathrm{d}_{002}$ and the $L_{c}$ when obtained without correction were found to be adequate when comparing different glassy carbon samples, all experiments under identical conditions.*

The (002) peaks were generally quite broad. A smooth curve was drawn through the profile and the values of $L_{c}$ reported are for the smoothed broad peak.

The (100) peaks of these carbons were not resolved from the (101) peak. So, strictly speaking, $L_{a}$ and $d_{100}$ cannot be calculated. However, to get some idea of the size of the crystallite in the $\vec{a}$ direction, $L_{a}$, was calculated from the unresolved (100) and (101) peaks which is 
designated as the (10) peak. The values of $d_{10}$ and $L_{a}$ should be interpreted accordingly.

\subsection{Real density measurement}

The real density of carbon samples is difficult to measure and sometimes becomes even conceptually elusive. The variation of micropore characteristics, e.g., pore size distribution, shape of the pores, etc., makes it quite difficult to obtain accurate and reproducible density on a routine basis. The absorption (and adsorption) characteristics and accessibility of the pore volume varies from fluid to fluid, hence the choice of the immersion fluid is very critical. The real density was first measured in a commercial helium pycnometer. Data for some of the glassy carbon yielded an apparent negative density, probably due to a rather large absorption of helium in the micropores of carbon; or by smaller, but variable, amounts of adsorption. As a result, densities were then measured by xylene immersion.

In most cases the xylene density was reproducible and slightly lower than the helium density. It was found that the grinding of samples in either alumina or tungsten carbide lined ball mills introduced enough wear materials from the liner and/or balls to cause a measurable difference in density. The presence of $\mathrm{Al}_{2} \mathrm{O}_{3}$ or WC was confirmed by X-ray analysis of the powders. Therefore, the sample was hand pulverized and screened to pass through a 100 mesh sieve thereby avoiding prolonged grinding.

\section{RESULTS AND DISCUSSION}

In order to check the functioning of the cell, several experiments were run with $\mathrm{Pt}$ on both sides of the electrolyte and then with identical graphite on both sides in order to verify that no stray emf was involved. The cell voltages measured were always less than $0.1 \mathrm{mV}$ in the entire temperature range of $600^{\circ}-1150^{\circ} \mathrm{C}$.

A rather extensive set of check runs (in the pertinent temperature and oxygen partial pressure range) were made to insure precision and otherwise check experimental procedures. A series of runs was carried out on oxides (NiO, $\mathrm{CoO}$, "FeO") with known thermodynamic properties in order to verify cell configurations, electrical and temperature measurement techniques, gas train functioning, thermal diffusion effects, and solid electrolyte composition. In all cases, extremely gratifying confirmations were found.

It was also demonstrated[11] that the cell yields a precise value for the standard Gibbs free energy change of the equilibria:

$$
\begin{gathered}
\mathrm{CO}(\mathrm{g})+\frac{1}{2} \mathrm{O}_{2}(\mathrm{~g})=\mathrm{CO}_{2}(\mathrm{~g}) \\
\mathrm{C} \text { (graphite) }+\mathrm{CO}_{2}(\mathrm{~g})=2 \mathrm{CO}(\mathrm{g}) .
\end{gathered}
$$

Therefore, all the thermodynamic criteria were fulfilled for a precise measurement of the equilibrium constants of the equilibrium: $\mathrm{C}_{\text {graphite }} \rightleftarrows \mathrm{C}_{\text {glassy carbon. }}$.

A summary of the thermal treatment of the glassy carbon samples used is shown in Table 1. It is conventional to describe the thermal history of carbon samples by specifying HTT (highest heat treating temperature), HTt (time at HTT) and the atmosphere at HTT.

The experimental data on two families of glassy carbon are shown in Fig. 2 and Fig. 4. Within each family only the HTT has been changed. The two families differ in the low temperature polymerization of the PFA resin. The

\begin{tabular}{|c|c|c|c|c|}
\hline Experiment & Sample \# & $\begin{array}{l}\text { HTT } \\
\left({ }^{\circ} \mathrm{C}\right)\end{array}$ & $\begin{array}{l}\mathrm{HTt} \\
\text { (hr) }\end{array}$ & $\begin{array}{c}\text { HTT Atmosphere } \\
\text { (Vacuum } \approx \times 10^{-7} \text { atms) }\end{array}$ \\
\hline ZC- 15 & UCAR-ZBY & * & $*$ & * \\
\hline$Z C-16$ & $321-13$ & 1060 & $\simeq 1$ & Vacuum \\
\hline ZC. -17 & $321-13$ & 1243 & $\simeq 1$ & Vacuum \\
\hline ZC. 18 & $321-13$ & 1510 & $\approx 1$ & Vacuum \\
\hline ZC -19 & $321-13$ & 1800 & $\simeq 1$ & Vacuum \\
\hline $\mathrm{ZC}-2 \mathrm{I}$ & $\begin{array}{l}\text { Beckwith } \\
\text { D-82-2 }\end{array}$ & 2000 & $*$ & $*$ \\
\hline $\mathrm{ZC}-23$ & $321-13$ & 2000 & $\simeq 1$ & Nitrogen \\
\hline $\mathrm{ZC}-24$ & $321-7$ & 1002 & $\simeq 1$ & Vacuum \\
\hline $\mathrm{ZC}-25$ & $321-7$ & 2000 & $\simeq 1$ & Nitrogen \\
\hline ZC-27 & $\begin{array}{l}\text { Hercules } \\
\text { H-54 }\end{array}$ & 1795 & $\simeq 1$ & Vacuum \\
\hline ZC-28 & $324-19$ & 1066 & $\simeq 1$ & Vacuum \\
\hline ZC-29 & $324-19$ & 1250 & $\simeq 1$ & Vacuum \\
\hline ZC-30 & $324-19$ & 1550 & $=1$ & Vacuum \\
\hline ZC-31 & $324-19$ & 1890 & $\simeq 1$ & Vacuum \\
\hline
\end{tabular}

Table 1. Summary of thermal treatment on glassy carbon samples

*Not known. 


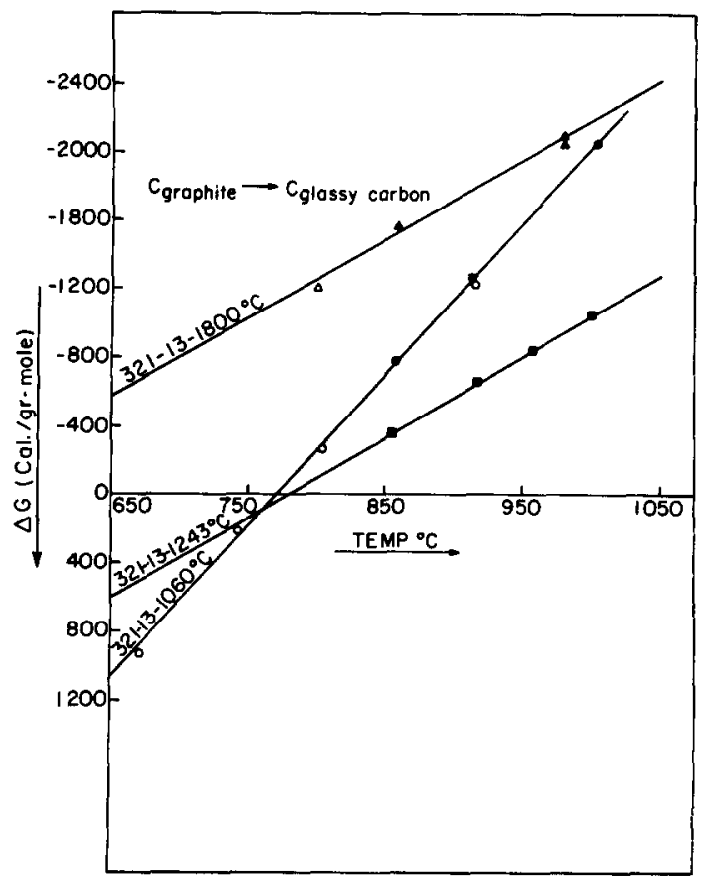

Fig. 2. Free energy-temperature relationship for 321-13 series glassy carbons differing only by HTT.

straight line behavior of the plots between $\Delta G$ (the Gibbs free energy change of the equilibrium: $\mathrm{C}_{\text {graphite }} \rightleftarrows \mathrm{C}_{\text {glassy carbon }}$ ) and temperature, confirms that no significant differences in heat capacity (and hence the vibrational contributions) exist between graphite and glassy carbons. The configurational (or residual) entropy and enthalpy are the slopes and intercepts at zero Kelvin, respectively. Additional results are shown in Fig. 3 for a commercial Beckwith vitreous carbon and for a pyrolized experimental resin (H-54) supplied by Hercules Chemical Company. The calculated values of $\Delta H(300-9200 \mathrm{cal} / \mathrm{g}$ mole) and $\Delta S\left(0.2-11.3 \mathrm{cal} / \mathrm{g}-\mathrm{mole}-{ }^{\circ} \mathrm{K}\right)$ along with the standard deviation and correlation coefficient of least squares fitted lines of $\Delta G$ vs $T$, for all the samples studied are given in Table 2. All the results show excellent correlation coefficients exceeding 0.990 in most cases, and a very small standard deviation, less than $\pm 300 \mathrm{cal} / \mathrm{g}$ mole.

The thermodynamic carbon activities in glassy carbon samples with respect to graphite as a standard state for carbon are listed at two temperatures $\left(600^{\circ} \mathrm{C}\right.$ and $\left.1000^{\circ} \mathrm{C}\right)$ in Table 3. The carbon activities in all the glassy carbon samples decrease with increasing temperature. Most of the experimental and commercially available samples of glassy carbon studied exhibit lower carbon activity than graphite at $1000^{\circ} \mathrm{C}$. Table 3 also shows $T_{c}$, the crossing point temperature, at which the carbon activity in both graphite and glassy carbon is unity.

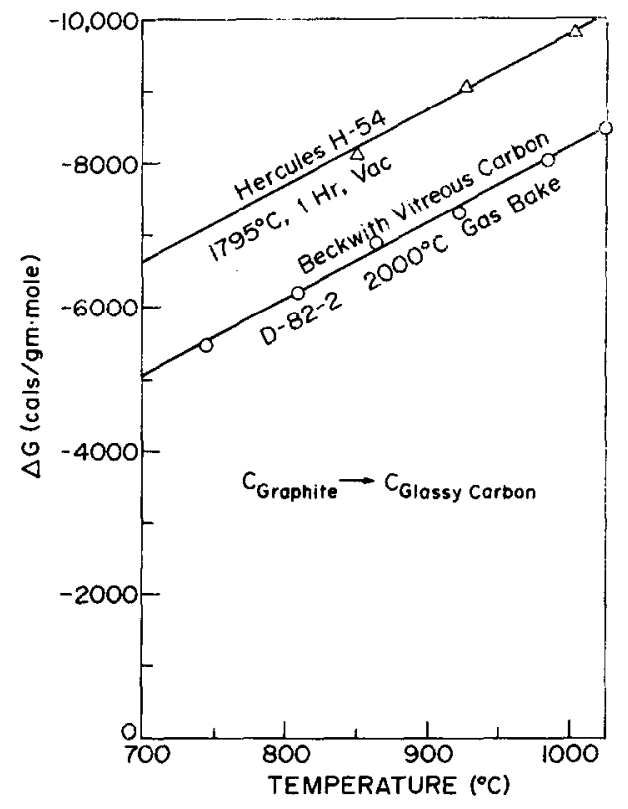

Fig. 3. Free energy-temperature relationship for Hercules and Beckwith glassy carbons.

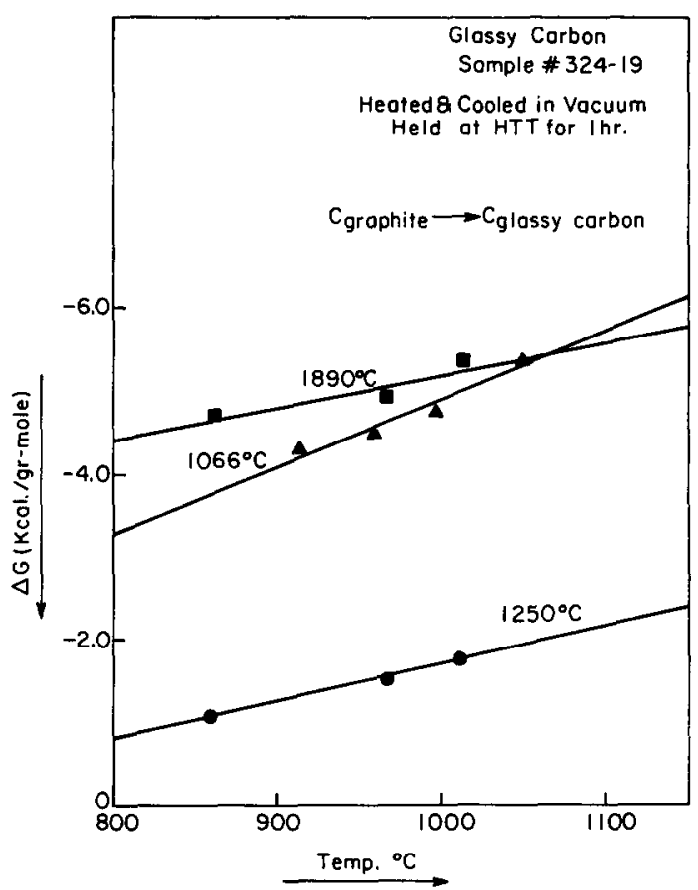

Fig. 4. Free energy-temperature relationship for 324-19 series glassy carbons differing only by HTT.

The results ( $\Delta H$ vs $\Delta S$ ) for all the samples studied are presented in graphical form in Fig. 5. On this figure the origin represents perfect crystalline hexagonal graphite 
Free energy change of the graphite-glassy carbon equilibrium

Table 2. Summary of data on thermodynamic measurements

\begin{tabular}{ccccc}
\hline Experiment & $\begin{array}{c}\Delta H \\
\text { (cal/g-mole) }\end{array}$ & $\begin{array}{c}\Delta S \\
\left.\text { (cal/g-mole- }{ }^{-} \mathrm{K}\right)\end{array}$ & $\begin{array}{c}\text { Standard Deviation } \\
\text { in } \Delta G \text { (cal/g-mole) }\end{array}$ & $\begin{array}{c}\text { Correlation } \\
\text { Coefficient }\end{array}$ \\
\hline ZC-15 & 300 & 0.2 & - & - \\
ZC-16 & 9200 & $8 \cdot 8$ & \pm 100 & 0.990 \\
ZC-17 & 4800 & $4 \cdot 6$ & \pm 100 & 0.999 \\
ZC-18 & 4200 & $4 \cdot 2$ & \pm 100 & 0.998 \\
ZC-19 & 3700 & 4.6 & \pm 100 & 0.994 \\
ZC-21 & 5200 & 10.5 & \pm 200 & 0.997 \\
ZC-23 & 7000 & 5.1 & \pm 200 & 0.995 \\
ZC-24 & 2750 & 3.1 & \pm 100 & 0.998 \\
ZC-25 & 4500 & 7.7 & \pm 100 & 0.994 \\
ZC-27 & 4500 & 11.3 & \pm 200 & 0.995 \\
ZC-28 & 5600 & 8.3 & \pm 300 & 0.969 \\
ZC-29 & 4,050 & 4.5 & \pm 100 & 0.997 \\
ZC-31 & 300 & 4.3 & \pm 300 & 0.937 \\
\hline
\end{tabular}

Table 3. Carbon activity (with reference to graphite as a standard state) in glassy carbons as a function of temperature

\begin{tabular}{cccc}
\hline Experiment & $a_{c}\left(\right.$ at $\left.600^{\circ} \mathrm{C}\right) a_{c}\left(\mathrm{at} 1000^{\circ} \mathrm{C}\right)$ & \multicolumn{1}{c}{$\begin{array}{c}T_{c} \\
\left({ }^{\circ} \mathrm{K}\right)\end{array}$} \\
\hline ZC-15 & 1.07 & 1.02 & 1500 \\
ZC-16 & 2.40 & 0.45 & 1045 \\
ZC-17 & 1.57 & 0.66 & 1043 \\
ZC-18 & 1.36 & 0.64 & 1000 \\
ZC-19 & 0.83 & 0.43 & 804 \\
ZC-21 & 0.10 & 0.04 & 495 \\
ZC-23 & 4.34 & 1.22 & 1372 \\
ZC-24 & 1.03 & 0.62 & 887 \\
ZC-25 & 0.28 & 0.12 & 584 \\
ZC-27 & 0.05 & 0.02 & 398 \\
ZC-28 & 0.39 & 0.14 & 675 \\
ZC-29 & 1.07 & 0.52 & 900 \\
ZC-31 & 0.14 & 0.13 & 70 \\
\hline
\end{tabular}

$(\Delta H=0 \cdot 0, \Delta S=0 \cdot 0)$. It is quite apparent that the various glassy carbons are remarkably different from one another and from graphite in thermodynamic properties. Hence, it seems more appropriate to think of "glassy carbon" as a broad class of materials rather than a single material. Various attempts to calculate the configurational entropy from assumed models (microcrystalline model, stacking fault model, and mixed bond model) of structure have been made [11]. The configurational enthalpy change can be interpreted in terms of missing atoms, strained bonds, and similar defects, while the entropy change can be related to the atomic disorder relative to perfect crystalline graphite.

Experiment $\mathrm{ZC}-15$ shows a trial run using a stress recrystallized graphite (UCAR-ZBY). In this case the emf was $\pm 1 \mathrm{mV}$ or less throughout the temperature range.

For many of the samples the equilibrium oxygen partial pressures are below $10^{-18}$ atmospheres. These conditions are marginal for the calcia-doped zirconia electrolytes.

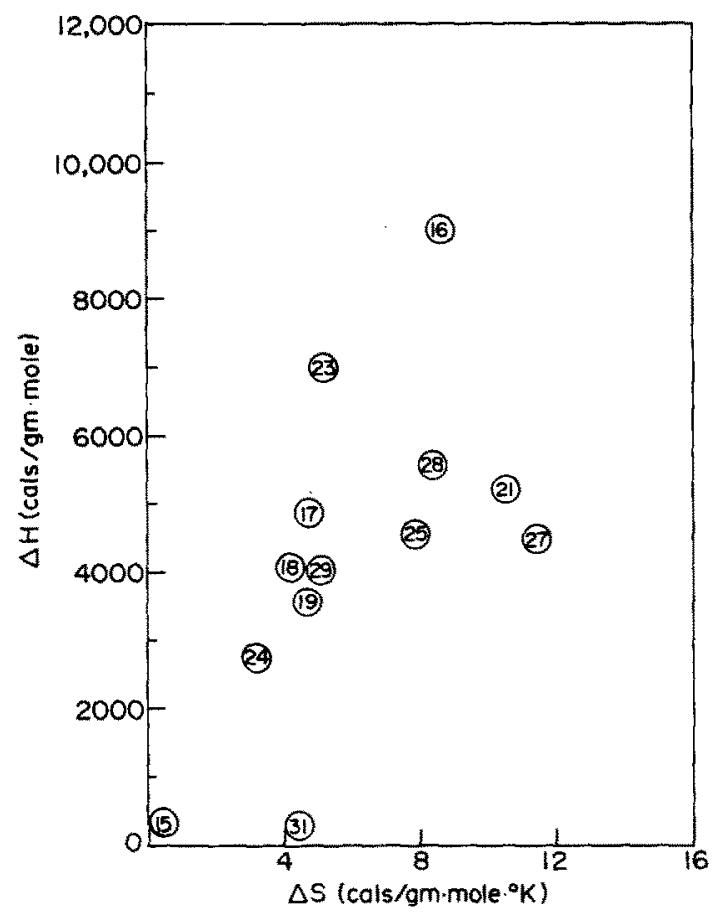

Fig. 5. Two parameter representation of glassy carbons.

Therefore, experiments were run with yttria-doped thoria electrolyte $\left(\mathrm{Th}_{0.85} \mathrm{Y}_{0.15} \mathrm{O}_{1.925}\right)$ on samples ( $\mathrm{ZC}-16$ and $\left.\mathrm{ZC}-19\right)$ where previous data were available from calcia-doped zirconia $\left(\mathrm{Zr}_{0.85} \mathrm{Ca}_{0.15} \mathrm{O}_{1.85}\right)$ electrolytes. The lower oxygen partial pressure limit for exclusive ionic conduction is considerably lower for thoria-based electrolytes than zirconia-based electrolytes. The experimental results of zirconia-based electrolyte for ZC-16 and ZC-19 were identical (within the error band of experimental accuracy) with thoria-based electrolyte. It was, therefore, concluded that calcia-doped zirconia electrolyte performs as an 
exclusive conductor of oxygen ions in the temperature and oxygen partial pressure range prevailing in the present experiments.

A theoretical study of the $\mathrm{C}-\mathrm{O}-\mathrm{H}$ equilibrium gas phase system has been done to estimate the upper bound of error introduced in the measured thermodynamic quantities due to any possible presence of hydrogen in the solid carbon [11]. The error was found to be negligible for a solid carbon containing as much as 10 atomic per cent hydrogen. Therefore, hydrogen could not account for the large measured free energy differences between graphite and glassy carbon.

The average weight loss in most of the glassy carbon samples (about $0.25 \mathrm{~g}$ ) during the entire duration of the experiments (about $3 \mathrm{~h}$ above $1000^{\circ} \mathrm{C}$, and about 3 days above $600^{\circ} \mathrm{C}$ ) was about 10 per cent. The measured thermodynamic quantities are not a function of the carbon burn-off, since experimental data within each run were produced (within limits of experimental uncertainty) while cooling and heating of the cell.

In the present study two series of glassy carbons (321-13 and 324-19) have been completed where only one major processing variable HTT was changed. The results are shown in Figs. 6 and 7, together with X-ray and real density data on the same samples (Table 4). The X-ray results show as usual an increasing $L_{c}$ and $L_{a}$, and decreasing $\mathrm{d}_{002}$ as the pyrolysis temperature is raised. While additional correlations may be possible, it appears that the wide angle $X$-ray data are not very sensitive indicators of the structural differences that influence the measured properties of glassy carbon.

The real density of carbon samples measured by xylene immersion method along with additional data on specific nitrogen surface area are also shown in Table 4. If it were

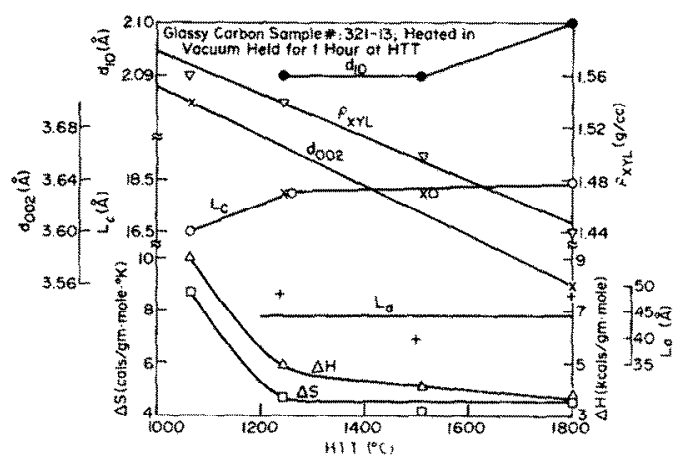

Fig. 6. Relation of X-ray and thermodynamic properties of 321-13 series glassy carbons.

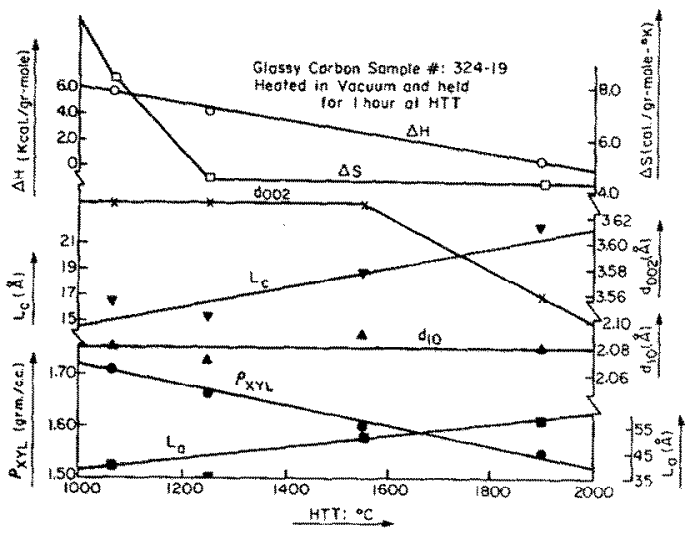

Fig. 7. Relation of X-ray and thernodynamic properties of 324-19 series glassy carbons.

Table 4. Summary of X-ray, surface area, and xylene density data

\begin{tabular}{|c|c|c|c|c|c|c|}
\hline Experiment & $\begin{array}{l}\text { Specific Nitrogen } \\
\text { Surface Area } \mathrm{m}^{2} / g\end{array}$ & $\begin{array}{c}\text { Xylene Density } \\
\rho_{\times \mathrm{x}}, \mathrm{g} / \mathrm{cc}\end{array}$ & $\stackrel{d_{002}}{\AA}$ & $\stackrel{L_{c}}{\AA}$ & $\stackrel{d_{10}}{\AA}$ & $\begin{array}{l}L_{a} \\
\AA\end{array}$ \\
\hline Graphite & - & 2.22 & 3.37 & $\begin{array}{l}\text { Very } \\
\text { hight }\end{array}$ & $2 \cdot 13$ & $\begin{array}{l}\text { Very } \\
\text { high }\end{array}$ \\
\hline$Z C-16$ & $72 \cdot 4$ & 1.56 & $3 \cdot 70$ & 16.5 & No vis. & No vis. \\
\hline ZC-17 & 56.6 & 1.54 & 3.63 & $18 \cdot 1$ & 2.09 & 47.5 \\
\hline ZC-18 & $51 \cdot 3$ & 1.50 & 3.63 & $18 \cdot 1$ & 2.09 & $39 \cdot 4$ \\
\hline ZC- 19 & 47.9 & 1.44 & 3.56 & 18.5 & $2 \cdot 10$ & 48.5 \\
\hline ZC-21 & - & 1.51 & 3.49 & 30.8 & $2 \cdot 10$ & 48.5 \\
\hline $\mathrm{ZC}-23$ & $\ldots$ & 1.45 & $3 \cdot 42$ & $32 \cdot 2$ & 2.09 & 61.0 \\
\hline ZC-24 & - & 1.52 & 3.69 & 17.5 & $\begin{array}{l}\text { No vis. } \\
\text { peak }\end{array}$ & $\begin{array}{c}\text { No vis. } \\
\text { peak }\end{array}$ \\
\hline $\mathrm{ZC}-25$ & - & 1.47 & 3.46 & 30.8 & $2 \cdot 10$ & $42 \cdot 0$ \\
\hline ZC-27 & - & 1.51 & 3.49 & 28.0 & 2.09 & 510 \\
\hline ZC-28 & - & 1.71 & 3.63 & 16.5 & 2.08 & 40.0 \\
\hline $\mathrm{ZC}-29$ & - & 1.66 & 3.63 & $15 \cdot 4$ & 2.07 & 35.8 \\
\hline ZC. 30 & - & 1.60 & 3.63 & 18.8 & 2.09 & 51.0 \\
\hline $\mathrm{ZC}-31$ & - & 1.55 & 3.56 & 22.4 & 2.08 & 57.3 \\
\hline
\end{tabular}


assumed that the micropores of glassy carbon are made up of monodispersed spheres and that the diameter of these pores increase with increasing HTT, as suggested by many small angle X-ray works [14] the decrease of both real density and surface area can be interpreted in terms of a transition of the micropore system of glassy carbons from many small pores at lower HTT to a fewer larger pores at higher HTT.

The configurational entropy and enthalpy show the expected trend-less disorder at higher HTT-however, it is apparent that not much entropy change occurs from $1250^{\circ}$ to $1800^{\circ} \mathrm{C}$. The enthalpy shows a somewhat larger change in the same range. The rate of lowering of $\Delta S$ is consistent with Franklin's[13] idea of progressive but limited graphitization of non-graphitizing carbons.

It seems that $\Delta H$ and $\Delta S$ are two independent structural parameters, e.g., a high value of entropy does not necessarily indicate high enthalpy values. There is a very strong correlation between $\Delta H$ and $L_{c}$, as both are strain related parameters. Thrower and Nagle[15] and Ergun [16] have pointed out that for the (002) peak, which is most used to compute $L_{c}$, the strain accounts for as much as 30 per cent of the peak broadening. In Fig. 6 where the results are plotted for the 321-13 series glassy carbons varying only in HTT, there is a sharp increase in the value of $L_{c}(16.5 \AA$ to $18.1 \AA)$ from $1060^{\circ} \mathrm{C}$ to $1243^{\circ} \mathrm{C}$, after which the rate of increase is slowed down (18.1 $\AA$ to $18.5 \AA$ ). The identical trend in the opposite direction is exhibited by $\Delta H$, i.e., a sharp decrease from $9200 \mathrm{cal} / \mathrm{g}$ mole to $4800 \mathrm{cal} / \mathrm{g}$-mole in the temperature range of $1060^{\circ} \mathrm{C}$ to $1243^{\circ} \mathrm{C}$ and then a relatively small decrease ( 4800 to $3700 \mathrm{cal} / \mathrm{g}$-mole) from $1243^{\circ}$ to $1800^{\circ} \mathrm{C}$. In Fig. 7 also a steady increase in $L_{c}$ is reflected by a steady decrease in $\Delta H$. It is worthwhile noting that $\Delta H$ for 324$19-1890^{\circ} \mathrm{C}(\mathrm{ZC}-31)$ is only $300 \mathrm{cal} / \mathrm{g}$-mole compared to $3700 \mathrm{cal} / \mathrm{g}$-mole for $321-13-1800^{\circ} \mathrm{C}(\mathrm{ZC}-19)$. This lower $\Delta H$ is reflected in higher $L_{r} \cdot(22.4 \AA$ for ZC-31 compared to $18.5 \AA$ for $Z C-19)$. The comparable values of $\Delta H$ in samples ZC- 17 and ZC-29 $(4800 \mathrm{cal} / \mathrm{g}$-mole and $4050 \mathrm{cal} / \mathrm{g}$ mole) show comparable values of $L_{c}(18 \cdot 1 \AA$ and $18 \cdot 8 \AA)$. These findings of strain relaxation are consistent with the formation of closed pores as indicated by the steady drop in xylene density in both Figs. 6 and 7.

Some studies have been reported in the literature $[17,18]$ where attempts have been made to correlate $\mathrm{d}_{002}$, the interlayer spacing and $p$, the probability of occurance of misoriented layers relative to an adjacent one. It is therefore logical to expect a correlation between $\Delta S$ and $\mathrm{d}_{\mathrm{nn} 2}$, since both $\Delta S$ and $p$ are atomic disorder parameters. For example, an identical value of $\mathrm{d}_{002}$ ( $3.63 \AA)$ in samples $\mathrm{ZC}-17$ and $\mathrm{ZC}-30$ reflects in very comparable values of $\Delta S\left(4.6\right.$ and $\left.4.5 \mathrm{cal} / \mathrm{g}-\mathrm{molc}-{ }^{\circ} \mathrm{K}\right)$. However, it is worthwhile to note that a given value of $d_{002}$ does not always correspond to a given disorder, $\Delta S$. For example, the Hercules H-54 sample (ZC-27) shows a roughly equal value of $d_{002}$ to that of $321-13-1800^{\circ} \mathrm{C}$ (ZC-19), but it has far higher disorder, i.e., $\Delta S$ of $11.3 \mathrm{vs}$ $4 \cdot 6 \mathrm{cal} / \mathrm{g}$-mole.

There is also some indication that the atmosphere at high temperature treatment is important. Sample 321-13 (ZC-23) shows a higher disorder after treatment to $2000^{\circ} \mathrm{C}$ in flowing nitrogen than $1800^{\circ} \mathrm{C}$ (ZC-19) sample in vacuum.

\section{CONCLUSIONS}

The following conclusions are drawn from the results of the experimental measurements of the configurational free cnergy change of the equilibrium: $\mathrm{C}_{\text {graphite }} \rightleftarrows \mathrm{C}_{\text {glassy carbon }}$.

(1) The measured Gibbs free energy change yields configurational (residual quantities at zero Kelvin) enthalpy and entropy changes which represent a two parameter measure of the structural differences between a given glassy carbon and graphite. The enthalpy change can be interpreted in terms of strain relaxation, while the entropy change can be related to the atomic disorder relative to perfect crystalline graphite.

(2) Many of the experimental and commercially available samples of glassy carbon studied exhibited at elevated temperature thermodynamic carbon activities lower than graphite. For various samples studied, the zero point entropy varied from 3.1 to $11.3 \mathrm{cal} / \mathrm{g}$-mole- ${ }^{\circ} \mathrm{K}$ which represents a large disorder relative to graphite. The glassy carbon samples displayed a wide variation in thermodynamic properties and hence it seems more appropriate to think of "glassy carbon" as a broad class of matcrials rather than a single material.

Acknowledgements - The authors wish to thank Mr. Robert B. Snow for his much needed help in sample preparation and measurements of xylene immersion density. The authors also wish to thank Mr. Mani R. Gupta and Mr. Justin Opoku for their help in the X-ray diffraction experiments. This research was sponsored by the Advanced Research Projects Agency under contract number DAHC15-71-C-0283. The editorial help of Mrs. Diane Lyster during the preparation of this manuscript is gratefully acknowledged.

\section{REFERENCES}

1. Kiukkola K. and Wagner C., J. Electrochem. Soc. 104, 308, 379 (1957).

2. Patterson J. W., Bogren E. C. and Rapp R. A., J. Electrochem. Soc. 114, 752 (1967).

3. Rapp R. A. and Shores D. A., Techniques of Metal Research Volume IV, Part 2, 123. Interscience Publishers (1970).

4. Ftsell T. H. and Flengas S. N., Chem. Rev. 70, 339 (1970).

5. Takahashi Y. and Westrum E. F. Jr., J. Chem. Thermo. 2, 847 (1970).

6. Yokoyama J., Murabayashi M., Takahashi Y. and Mukaibo T., Tanso 65, 44 (1971).

7. Shen M. C. and Eisenberg A., Rubber Chem. Technol. 43, 95 (1970). 
8. Lewis J. B., Murdoch R. and Moul A. N., Nature 221, 1137 (1969).

9. Boehm H. P. and Coughlin R. W., Carbon 2, 1 (1964).

10. Gordon A. R., J. Chem. Phys. 1, 308 (1933).

11. Das S. K., Ph.D. Thesis, The University of Michigan. Ann Arbor (1974).

12. Short M. A. and Walker P. L. Jr., Carbon 1, 1 (1963).
13. Fraklin R. E., Proc. Roy. Soc. A 209, 196 (1951).

14. Rothwell W. S., J. Appl. Phys. 30, 1840 (1968).

15. Thrower P. A. and Nagle, D. C., Carbon 11, 663 (1973).

16. Ergun S., Phys. Rev. B1, 3371 (1970).

17. Franklin R. E., Acta Cryst. 4, 253 (1951).

18. Ruland W., Chemistry and Physics of Carbon, Vol. 4, 1 (1968). 